Gut, 1982, 23, 485-489

\title{
Mucin secretion in inflammatory bowel disease: correlation with disease activity and dysplasia
}

\author{
M EHSANULLAH, M ISABEL FILIPE*, and B GAZZARD \\ From the Department of Histopathology and the Gastroenterology Unit, Westminster Medical School and \\ Hospital, London
}

SUMMARY When rectal biopsies from 65 patients with ulcerative colitis and 20 patients with Crohn's disease were stained for mucins, an abnormal pattern (excess of sialomucins) was seen in about half of them. This is in contrast with 65 cases of non-specific proctitis where the mucin pattern of rectal biopsies was normal in all except one case. The abnormal mucin secretion in patients with ulcerative colitis was apparently related to the activity, duration, and extent of the disease. All biopsies with dysplasia showed predominant sialomucin staining except one. All biopsies showing sialomucins during remission also had dysplasia, while during active disease a number of biopsies had increased sialomucins without the evidence of dysplasia. It is not known if such cases will subsequently develop morphological atypia.

Alterations in the composition of mucous secretion have been described in the gastrointestinal tract in association with malignancy. ${ }^{1-6}$ In the colon these changes are characterised by an increased proportion of sialomucins in contrast with normal biopsies where sulphomucins predominate. The findings of these abnormal mucin patterns in solitary ulcer syndrome ${ }^{7}$ however, raised the question whether such changes were non-specific and simply related to inflammation.

We, therefore, decided to study mucous secretion patterns of other inflammatory bowel diseases. We were particularly interested to see if alteration in mucin composition was related to the histological severity, extent, and duration of the inflammation or the presence of dysplasia and whether such changes can be used to distinguish ulcerative colitis, Crohn's disease, and non-specific proctitis.

\section{Methods}

\section{PATIENTS}

A total of 240 rectal biopsies were examined from 65 cases of ulcerative colitis, 20 of definite colonic Crohn's disease, and 65 of non-specified proctitis collected over a four-year period (1975-79). Cases of ulcerative colitis complicated with carcinoma or

* Address for reprints: Dr M Isabel Filipe, Department of Histopathology, Westminster Medical School, Udall Street, London, SW1P 2PP.

Received for publication 9 November 1981 treated by colectomy and ileorectal anastomosis were excluded, and these will be reported separately.

\section{CRITERIA FOR DIAGNOSIS}

Ulcerative colitis

Ulcerative colitis was diagnosed by clinical history, involvement of the rectum on sigmoidoscopy, combined with the findings of barium studies and colonoscopy, absence of strictures, fistulae, and small bowel involvement. All patients had a rectal biopsy showing either a diffuse mixed or chronic inflammatory infiltrate in the lamina propria (active or resolving phase), or evidence of past disease with shorter and distorted crypts but little or no inflammation and good preservation of mucous secretion (remission phase). In active disease ulceration and crypt abscesses were common and mucous depletion varied in proportion to the severity of the inflammation.

\section{Crohn's disease}

Crohn's disease was diagnosed by 'classical' histological changes on rectal biopsy with the presence of non-caseating epitheloid granulomas and barium studies or colonoscopy. All patients had a barium meal and follow through and in some involvement of small bowel was noted.

Non-specific proctitis

Non-specific proctitis was diagnosed if the inflam- 
mation was limited to the rectum, with normal mucosa being seen above the inflammation on sigmoidoscopy and a normal barium enema. Rectal biopsies in all patients revealed features similar to those seen in ulcerative colitis. Note was taken of the duration, severity, and extent of the disease.

DEGREE AND EXTENT OF HISTOLOGICAL CHANGES IN ULCERATIVE COLITIS

The biopsies were classified both in terms of histological disease activity (mild, moderate, or severe) and phase of disease (active, resolving, and remission) according to criteria which have been used in other studies. ${ }^{8-11}$ To diagnose dysplasia the cytological changes in nuclei and nucleoli, abnormal mitotic figures, loss of nuclear polarity, increased nuclear-cytoplasm ratio, and decreased mucus secretion were considered and graded. Other features of dysplasia such as undifferentiated 'clear cells' along the crypt, basal cell hyperplasia, and 'transitional type' of epithelium were recorded. ${ }^{11} 12$ In addition 33 biopsies from miscellaneous large bowel conditions were examined histologically and histochemically, and used as control group. These include irritable bowel syndrome, amyloid, melanosis coli, piles, anal fissure, ameobic dysentery, infective diarrhoea, irradiation proctitis, Hirschprung's disease, and chronic constipation.

\section{MUCOUS SECRETION}

In the normal colonic mucosa, goblet cells along the whole or two-thirds lower crypt secrete predominantly sulphomucins, while in the upper crypt and surface epithelium both sulpho- and sialomucins are produced. This 'normal mucous pattern' may vary, with both types of acid mucins sulpho- and sialomucins being secreted in equal proportions along the crypt epithelium or sialomucins being predominant in the upper half of the crypt (mixed pattern). We consider it abnormal when the majority of goblet cells in the crypt secrete sialomucins. All biopsies were reviewed without the knowledge of previous results and diagnosis.

\section{STAINING METHODS}

All biopsies were fixed in $10 \%$ formol-saline and paraffin sections were stained with haematoxylineosin. The following techniques were used to assess the amount and types of mucins: periodic-acid Schiff $(P A S)^{13}$ and high iron-diamine-alcian blue (HID$\mathrm{AB})^{14}$ to distinguish neutral, sulpho-, and sialomucins.

Statistical analysis used the Fisher-exact probability test.

\section{Results}

\section{ULCERATIVE COLITIS}

The Tables show the mucin changes as normal, mixed pattern or sialomucins in the active, resolving or remission phases of ulcerative colitis. As the mixed mucin pattern and the resolving stage of ulcerative colitis are subjective histological changes susceptible to variations in interpretation, the biopsies showing these changes have been excluded from the statistical analysis. These results, which are included in the Tables, show that the biopsies with resolving colitis produce mucin changes which are intermediate between the biopsies of active disease and those in the stage of remission. A total of 120 rectal biopsies from 65 patients were studied, but it was not possible to accurately assess the extent and duration of disease in five cases.

\section{DISEASE ACTIVITY}

Forty-six out of $81(57 \%)$ biopsies during active phase but only five out of $26(19 \%)$ in remission show the presence of sialomucins. In the active phase, the frequency of predominant sialomucins staining seems to be related to the histological severity of the disease, being found in $45 \%$ and $61 \%$ of the cases with mild and severe inflammation respectively $(p=0.01)$ (Tables 1 and 2$)$.

\section{EXTENT OF DISEASE}

In the active phase the presence of sialomucins seems more pronounced in total (69\% of biopsies) than left-sided colitis ( $48 \%$ of biopsies), but these differences are not statistically significant. The difference in the remission phase, however, is significant with $27 \%$ of biopsies from total colitis showing predominance of sialomucins compared with $12 \%$ in left-sided colitis.

\section{DURATION OF DISEASE}

This seems to influence mucin change only during remission. None of the biopsies from nine patients who had ulcerative colitis for less than 10 years

Table 1 Mucin secretion patterns during active, resolving, and remission phases of ulcerative colitis

\begin{tabular}{llll}
\hline Mucins & $\begin{array}{l}\text { Active } \\
(81)\end{array}$ & $\begin{array}{l}\text { Resolving } \\
(13)\end{array}$ & $\begin{array}{l}\text { Remission } \\
(26)\end{array}$ \\
\hline NMP & 18 & 9 & 20 \\
Mixed & 17 & 1 & 1 \\
Sialo & 46 & 3 & 5 \\
\hline
\end{tabular}

NMP: normal mucin pattern (sulphomucins).

Mixed: sulpho+sialomucins (dominant sulphomucins). Sialo: sialomucins. 
Table 2 Mucus secretion patterns during active phase of ulcerative colitis

\begin{tabular}{llll}
\hline Mucins & $\begin{array}{l}\text { Mild } \\
\text { (20) }\end{array}$ & $\begin{array}{l}\text { Moderately } \\
\text { active } \\
(27)\end{array}$ & $\begin{array}{l}\text { Severely } \\
\text { active } \\
(34)\end{array}$ \\
\hline NMP & 9 & 6 & 3 \\
Mixed & 2 & 5 & 10 \\
Sialo & 9 & 16 & 21 \\
\hline
\end{tabular}

NMP: normal mucin pattern (sulphomucins).

Mixed: sulpho+sialomucins (dominant sulphomucins).

Sialo: sialomucins.

revealed predominance of sialomucins compared with five biopsies with abnormal mucin pattern taken from 17 patients who were in remission and had disease for more than 10 years.

DYSPLASIA

Dysplasia was present in 33 out of 81 biopsies taken in the active phase of the disease $(40 \%)$, while the corresponding figure for the remission phase was $19 \%$ (five out of 26 biopsies). Predominance of sialomucins seems to be related to the presence of dysplasia in both active and the remission phases. Of 46 biopsies, with histological evidence of active disease and sialomucins, 32 also had dysplasia, while only one biopsy revealed dysplasia in the presence of active disease with normal mucins $(\mathrm{p}<0 \cdot 0005)$ (Table 3). This relationship is even more apparent in remission where sialomucins were noted only in biopsies with dysplasia. All but one of the patients in remission with histological evidence of dysplasia and predominance of sialomucins had total colitis.

\section{CROHN'S DISEASE}

Twenty out of 42 rectal biopsies from patients with Crohn's disease showed sialomucins. None of the biopsies examined showed dysplasia (Table 4). As inflammation in this disease is patchy, it is not possible to assess the effects of disease activity on mucin secretion. The extent (colonic or small bowel+colonic) and duration of disease had no effect on mucin secretion patterns.

Table 3 Correlation between disease activity, dysplasia, and mucin secretion patterns

\begin{tabular}{lll}
\hline & $\begin{array}{l}\text { Biopsies } \\
\text { (no.) }\end{array}$ & $\begin{array}{l}\text { Biopsies with } \\
\text { dysplasia } \\
\text { (no.) }\end{array}$ \\
\hline Active disease+sialomucins & 46 & 32 \\
Active disease+NMP & 18 & 1 \\
Remission +NMP & 20 & 0 \\
Remission+sialomucins & 5 & 5 \\
\hline
\end{tabular}

NMP: normal mucin pattern (sulphomucins).
Table 4 Mucin secretion patterns in retation to extent of disease in Crohn's disease

\begin{tabular}{lcc}
\hline & Terminal-ileum + colon & Colon only \\
\hline NMP & 15 & 2 \\
Mixed & 3 & 2 \\
Sialo & 13 & 7 \\
Total & 31 & 11 \\
\hline
\end{tabular}

NMP: normal mucin pattern (sulphomucins).

Mixed: sulpho+sialomucins (dominant sulphomucins).

Sialo: sialomucins.

NON-SPECIFIC PROCTITIS

Sialomucins were dominant in only one out of 78 rectal biopsies from 65 patients with non-specific proctitis. In this patient mucin composition reverted to normal two years later when he was asymptomatic.

\section{MISCELLANEOUS}

All biopsies from a variety of non-inflammatory non-neoplastic colonic diseases revealed a normal mucous pattern.

\section{Discussion}

In biopsy material, it is sometimes difficult to distinguish between the various inflammatory bowel diseases. The two main entities, ulcerative colitis and Crohn's disease, present many common features and in the absence of granulomas, which are seen in only $60 \%$ of the cases, the distinction between the two in a single rectal biopsy is not always possible. ${ }^{815}$ The histological assessment is subjective and relies on a combination of criteria which are often lost in a superficial rectal biopsy because of the patchy nature of the inflammatory process in Crohn's disease and its transmural involvement. The preservation of mucous secretion in Crohn's disease, even in the presence of marked inflammation, and its depletion in ulcerative colitis, though helpful, is not a reliable criterion as a similar picture is found in the resolving phase of ulcerative colitis. We hoped that this difference in quantitative mucin assessment would also be mirrored by qualitative changes which would be of value in the differential diagnosis of these two conditions. Biopsies taken from patients with Crohn's disease, however, and ulcerative colitis both showed the presence of abnormal mucins in almost the same number of cases. The synthesis of complete glycoproteins which progresses with cell maturation can be impaired by genetic and environmental factors. ${ }^{16} 17$ Biochemical analysis of mucin composition in ulcerative colitis persistently showed 
abnormalities of the carbohydrate component, particularly high levels of mannose, and the aminoacids with lower content of serine and threonine. ${ }^{1819}$ Alterations in the enzymes involved in glycoprotein synthesis have also been reported in Crohn's disease. ${ }^{20}$ Thus, as it might be expected, our results demonstrate qualitative changes in mucins in both ulcerative colitis and Crohn's disease which may represent increased cell turnover in a mucosa subjected to constant damage. ${ }^{21}$ In view of this, the finding of a consistently normal mucin pattern in non-specific proctitis is surprising, and perhaps suggests different cell kinetics resulting from mucosal damage in this condition.

One of the problems in histological interpretation of biopsy material from ulcerative colitis is the assessment of the cancer risk in patients with epithelial dysplasia. Its value is limited by the fact that it is not a constant finding in carcinoma, it may be present without the development of neoplasia and it is a focal condition. It is particularly difficult to decide in the presence of inflammation whether the epithelial atypia is a precarcinomatous change or post-inflammatory. ${ }^{810} 22$ While these problems can be lessened with multiple colonoscopic and rectal biopsies and more careful endoscopic search for suspicious areas of dysplasia, we have previously suggested $^{4}$ that a study of qualitative differences in mucin secretion might also be helpful in predicting the development of cancer in patients with colitis. Our recent results indicate, however, that sialomucins are intimately related both to dysplasia and the severity of the inflammation. Thus, are sialomucins to be regarded only as a non-specific response to inflammation? In support of this argument is the finding of abnormal mucins in the absence of dysplasia in Crohn's disease and the solitary-ulcer syndrome. ${ }^{7}$

In favour of a close relationship between the occurrence of dysplasia and abnormal mucins is the presence of normal mucins in non-specific proctitis and in other miscellaneous conditions of large bowel even when inflammation is severe. Further evidence of this relationship is the coexistence of dysplasia and sialomucins in rectal biopsies taken from the patients with ulcerative colitis during the remission phase in the absence of inflammation.

An association between dysplasia and abnormal mucins would be logical, as there is evidence of impaired cell maturation in the dysplastic epithelium with the gradual replacement of the mature cell population of the normal mucosa by intermediate and immature cell types. This might result in incomplete glycoproteins being produced perhaps similar to those synthesised by mitotically active intestinal cells and their counterparts in both neoplasia and fetal gut. ${ }^{23}$ In the latter, sialomucins are secreted in the early stages of development with sulphomucins appearing later. ${ }^{24}$

There were in this study a group of patients with active disease and sialomucins but no dysplasia. It is possible that such cases indicate the first changes of dysplasia, preceding the morphological atypia, and, in biopsies taken on subsequent occasions, the typical histological features will develop. Alternatively, the mucin changes may represent a non-specific reaction which regresses when the inflammation ceases. The only way to answer this question is to assess mucin changes in rectal biopsies in a group of patients followed-up over several years. This study is now in progress.

We would like to thank $\mathrm{Mr} \mathrm{D}$ Timlin for the statistical analysis and Mrs K Matharu for secretarial assistance; and all the technical staff for their excellent work. Also our surgical and clinical colleagues at the Westminster Hospital, and Dr S Kenwright (consultant physician, William Harvey Hospital, Ashford, Kent) for the biopsy material. We are also grateful to the Cancer Research Campaign for financial assistance.

\section{References}

1 Goldman $H$, Ming SC. Mucins in normal and neoplastic gastrointestinal epithelium. Histochemical distribution. Arch Pathol 1968; 85: 580-6.

2 Filipe MI, Branfoot AC. Abnormal patterns of mucous secretion in apparently normal mucosa of large intestine with carcinoma. Cancer 1974; 34: 282-90.

3 Culling CFA, Reid PE, Worth AJ, Dunn WL. A new histochemical technique of use in the interpretation and diagnosis of adenocarcinoma and villous lesions in the large intestine. J Clin Pathol 1977; 30: 1056-62.

4 Filipe MI. Mucins in the human gastrointestinal epithelium: A review. Invest Cell Pathol 1979; 2: 195-216.

5 Jass J, Filipe MI. A variant of intestinal metaplasia associated with gastric carcinoma. A histochemical study. Histopathology 1979; 3: 191-9.

6 Montero C, Segura DI. Retrospective histochemical study of mucosubstances in adenocarcinomas of the gastrointestinal tract. Histopathology 1980; 4: 281-91.

7 Ehsanullah M, Filipe MI, Gazzard B. Morphological and mucous secretion criteria for differential diagnosis of solitary ulcer syndrome and non-specific proctitis. $J$ Clin Pathol 1982; 35: 26-30.

8 Price $\mathrm{AB}$, Morson $\mathrm{BC}$. Inflammatory bowel disease. The surgical pathology of Crohn's disease and ulcerative colitis. Human Pathol 1975; 6: 7-29.

9 Yardley JH, Donowitz M. Colorectal biopsy in inflam- 
matory bowel disease. In: Yardley JH, Morson BC, Abell MR, eds. The gastrointestinal tract. Baltimore: Williams and Wilkins, 1977: 50-94.

10 Morson BC, Dawson IMP. In: Gastrointestinal pathology. Oxford: Blackwell Scientific, 1979.

11 Lennard-Jones JE, Morson BC, Ritchie JK, Shove DC, Williams CB. Cancer in colitis: assessment of the individual cancer risk by clinical and histological criteria. Gastroenterology 1977; 73: 1280-9.

12 Riddell $\mathrm{RH}$. The precarcinomatous phase of ulcerative colitis. In: Morson BC, ed. Current topics in pathology. Heidelberg: Springer, 1976; 63: 179-219.

13 Pearse AGE. In: Histochemistry "theoretical and applied". Vol. 1. London: Churchill Livingstone, 1968.

14 Spicer SS. Diamine methods for differentiating mucosubstances histochemically. J Histochem Cytochem 1965; 13: 211-34.

15 Chambers TJ, Morson BC. Large bowel biopsy in the differential diagnosis of inflammatory bowel disease. Invest Cell Pathol 1980; 3: 159-73.

16 Florey HW. The secretion of mucus and inflammation of mucous membranes. In: Lord Florey, ed. General pathology. London: Lloyd Luke, 1970: 195.
17 La Mont JT, Ventola A. Galactosyltransferase in fetal, neonatal and adult colon: relationship to differentiation. Am J Physiol 1978; 235: E213-7.

18 Teague RH, Fraser D, Clamp JR. Changes in monosaccharide content of mucous glycoproteins in ulcerative colitis. Br Med J 1973; 2: 645-6.

19 Clamp JR. Gastrointestinal mucus. In: Wright R, ed. Recent advances in gastrointestinal pathology. London: Saunders, 1980.

20 Goodman MJ, Skinner JM, Truelove SC. Abnormalities in the apparently normal bowel mucosa in Crohn's disease. Lancet 1976; 1: 275-78.

21 Eastwood GL, Trier JS. Epithelial cell renewal in cultured rectal biopsies in ulcerative colitis. Gastroenterology 1973; 64: 383-90.

22 Riddell RH. Dysplasia in inflammatory bowel disease. Clin Gastroenterol 1980; 9: 439-58.

23 Isselbacher $\mathrm{KJ}$. The intestinal cell surface: some properties of normal, undifferentiated and malignant cells. Ann Intern Med 1974; 81: 681-6.

24 Lev R. A histochemical study of glycogen and mucin in developing human foetal epithelia. Histochem $J$ 1968; 1: $152-65$. 